\title{
Equipoise Is a Slippery Eel
}

\author{
Sanjay Kalra ${ }^{1}$ \\ ${ }^{1}$ Department of Endocrinology, Bharti Hospital, Karnal, Haryana, \\ India
}

J Soc Health Diab 2019;7:43-44

\section{Introduction}

The word "equipoise" is a versatile one. Used as a noun, it implies a "balance of forces or interests," or a "counterbalance or balancing force." As a verb, it is used to convey the act of balancing or counterbalancing. ${ }^{1}$ The use of this word, however, has fallen dramatically over the past century. Is this because the concept of equipoise is difficult to achieve?

In this editorial, we enumerate and discuss the domains of equipoise, as related to diabetes care ( $\mathbf{- T a b l e ~} \mathbf{1}$ ), and wonder if equipoise will always be a slippery eel.

\section{The Spectrum of Equipoise}

In diabetes care, experts have been using the terms "information equipoise," "clinical equipoise," "glycemic equipoise," and "emotional equipoise."-5 We add to these, "vasculometabolic equipoise," "equipoised intrusion," and "community equipoise."

For the diabetes care professional, equipoise is a multifaceted construct. Equipoise is a target, as well as a tool to achieve this target. In diabetes management, one aims to

Table 1 Equipoise in diabetes
Related to the patient
- Emotional equipoise
- Glycemic equipoise
- Vasculometabolic equipoise
Related to the professional
- Emotional equipoise
- Professional equipoise
Related to family/community
- Community equipoise
Related to interaction and treatment
- Therapeutic equipoise
- Information equipoise
- Equipoised intrusion
Related to cardiovascular trials
- Glycemic equipoise

create a stable health status, balancing glycemic control with the potential risk of hypoglycemia. ${ }^{6}$ This can be termed glycemic equipoise, though this phrase is used more often in the context of cardiovascular outcomes trials. ${ }^{4}$

\section{Equipoise as a Target}

Management strategies also try to achieve an equipoise of other vasculometabolic markers, including weight, blood pressure, and lipids. Mandate from regulatory agencies also demands demonstration of cardiovascular equipoise, or safety, with newly developed glucose-lowering drugs. ${ }^{7}$ Put together, the state of a comprehensive diabetes control can be termed as vasculometabolic equipoise. This implies that all vascular and metabolic aspects of health are given equally efficiently. In a similar fashion, endocrine equipoise may be taken to mean optimal "glucocrinological" health, balancing the function of all endocrine glands in addition to the pancreas.

Apart from the biomedical markers discussed earlier, there is a need to ensure emotional equipoise, or good psychosocial health, in persons living with diabetes. Such persons should be able to view diabetes as a part of life, and to ensure that it does not disturb the equilibrium of their personal or social life. ${ }^{8}$ The family in particular, and society at large, should be encouraged to view persons living with diabetes with equipoise, offering them the same opportunities that their peers get. Such a state can be described as community equipoise.

\section{Equipoise as a Tool}

To achieve this target, one needs to use equipoise as a tool. The diabetes care professional should remain emotionally equipoised or balanced, when confronted with challenging patients or difficult situations. ${ }^{8}$ She or he should endeavor to ensure information equipoise with the patient, so that shared decision making can be practiced in a responsible patient-centric manner. Information equipoise between two partners implies that both have access to similar information and knowledge. ${ }^{9}$ This, in turn, fosters similar attitudes and promotes similar decisions, thus facilitating taking concordance in management plans.
License terms

()(1) $\Theta \circledast$ 
At times, diabetes therapy may intrude unnecessarily into a patient's life. In such cases, one must balance the advantages of tight glycemic control with the overall impact of disease on quality of life. A fair compromise would be to aim for equipoised intrusion, that is, balancing the rigidity of therapy with the flexibility of lifestyle.

\section{Equipoise in Summary}

It is thus clear that the construct of equipoise embraces multiple stakeholders: the person living with diabetes (emotional equipoise, glycemic equipoise, and vasculometabolic equipoise), the diabetes care professional (emotional equipoise and professional equipoise), the family, and the community (community equipoise). It also addresses the physician-patient relationship (information equipoise and nature of treatment [equipoise intrusion]). The adjective has also been used with reference to cardiovascular outcome trials (glycemic equipoise) (-Table $\mathbf{1}$ ).

\section{Equipoise in Therapeutics}

More often than not, one is faced with multiple management options, all of which have their advantages and limitations. This represents a situation of "therapeutic equipoise," and is best handled by discussing various options with these patients. There is much more to equipoise, therefore, than what meets the eye. The dismal status of diabetes care across the world shows that we are far from reaching optimal balance in our fight against the epidemic. Till we create a synergistic and sustained, effort to understand this multidimensional balance, equipoise will remain a slippery eel.

\section{Conflict of Interest}

None declared.

\section{Acknowledgment}

Hitesh Punyani (New Delhi), Sameer Aggarwal (Rohtak), and Ashish Sehgal (Karnal) have contributed immensely to the conceptualization of this concept.

\section{References}

1 Equipoise. Available at: https://www.merriam-webster.com/ dictionary/equipoise. Accessed July 10, 2019

2 Elwyn G, Edwards A, Kinnersley P, Grol R. Shared decision making and the concept of equipoise: the competences of involving patients in healthcare choices. $\mathrm{Br} \mathrm{J}$ Gen Pract 2000;50(460):892-899

3 Freedman B. Equipoise and the ethics of clinical research. N Engl J Med 1987;317(3):141-145

4 Kalra S, John M, Unnikrishnan AG. Glycemic equipoise. Indian J Endocrinol Metab 2017;21(1):18-20

5 Kalra S, Joshi A, Kalra B, et al. Bhagavad Gita for the physician. Indian J Endocrinol Metab 2017;21(6):893-897

6 Kalra S, Baruah MP, Sahay R, Kishor K. Pentads and hexads in diabetes care: numbers as targets; numbers as tools. Indian J Endocrinol Metab 2017;21(6):794-796

7 John M, Gopalakrishnan Unnikrishnan A, Kalra S, Nair T. Cardiovascular outcome trials for anti-diabetes medication: a holy grail of drug development? Indian Heart J 2016;68(4):564-571

8 Kalra S, Das AK, Baruah MP, et al. Euthymia in diabetes: clinical evidence and practice-based opinion from an international expert group. Diabetes Ther 2019;10(3):791-804

9 Kalra S, Unnikrishnan AG, Baruah MP. Interaction, information, involvement (the 3I strategy): rebuilding trust in the medical profession. Indian J Endocrinol Metab 2017;21(2):268-270 